\title{
Impact of policies regulating foreign physician migration to Switzerland: a modelling case study in anaesthesia
}

\author{
Guy Haller ${ }^{1,2^{*}}$, Christophe Combescure ${ }^{3}$, Chantal Mamie ${ }^{1}$, Davide Zoccatelli ${ }^{1}$ and François Clergue ${ }^{1}$
}

\begin{abstract}
Background: Several countries have developed policies that restrict or limit duration of stay, clinical privileges or the number of residency permits allocated to migrating physicians. Switzerland is currently preparing a new law limiting overall foreign immigration. The impact of such restrictive policies is currently unknown. In a case study of anaesthesia care in Switzerland we modelled, trends in the size of physicians' workforce until 2024, following the implementation of a strict quota policy for foreign medical trainees.
\end{abstract}

Methods: We developed a computer-based Markov model with Monte-Carlo simulations to project, in the context of a strict quota policy for foreign trainees, supply and demand for anaesthesia positions until 2024. We used data from a cross-sectional study performed in the French- and Italian-speaking cantons of Switzerland and the Health dataset from the OECD.

Results: With 8 to $12(95 \% \mathrm{Cl} 4-20)$ anaesthetists retiring per year, the implementation of strict quotas of foreign graduates would result in a $38 \%$ decrease in the number of anaesthetists in intermediary (senior registrars) positions by 2024. This decrease would be particularly important in district hospitals where nearly half (49\%) of the non-Swiss anaesthetists are practising. Swiss graduates are unlikely to balance the shortage. Despite efforts by Swiss universities to increase the number of medical graduates, their number has dropped from 10.5 to 9.7/100 000 inhabitants between 2000 and 2012, due to the growth of the population.

Conclusions: This case study in Latin Switzerland shows that a restrictive policy limiting foreign immigration of trainees would result in a major deficit in the number of anaesthetists available to meet population needs. These aspects should be carefully considered when countries develop restrictions and limitations of foreign immigration.

\section{Background}

In many countries, growing efforts are devoted by healthcare authorities to the provision of high quality of care to the population. This implies that an appropriate balance between healthcare needs and healthcare workforce provision is maintained. Several studies have for instance demonstrated that there was a significant correlation between physician and nurse density and improved patient outcomes [1-3]. This is why forecasting

\footnotetext{
*Correspondence: guy.haller@hcuge.ch

'Division of Anaesthesia, Department of Anaesthesiology, Pharmacology and Intensive Care University Hospitals of Geneva, 4, rue Perret-Gentil, 1211 Genève 14 , Switzerland

${ }^{2}$ Health Services Management and Research Unit, Department of Epidemiology \& Preventive Medicine, Monash University, Melbourne, Australia

Full list of author information is available at the end of the article
}

models have been developed to ensure that this balance is maintained [4]. There are two types of forecasting models: demand-based models that inform need by examining the amount of health care services needed in the future, based on projected size, demographic and healthcare profile of the population and supply projection models that estimate workforce needs to maintain current standards and volume of services per capita [5]. While both forecasting models are used across countries, the supply-side model is the most commonly used method, particularly for physicians [6]. Usually, a defined ratio of physicians per 1000 inhabitants is determined and adjusted to the forecasted population increase (or decrease) accordingly. Then, the number of students allowed to enter medical schools is fixed according to the forecasted need. This method named the "numerus 
clausus", is in force in nearly all countries part of the Organisation for Economic Co-operation and Development (OECD), except Ireland and Austria [7].

Despite its wide dissemination, this approach has several weaknesses. Population forecasting models provide only estimates with confidence intervals and not exact numbers. Thus, the exact number of physicians to be trained in medical schools cannot be defined accurately. Furthermore, medical careers' and speciality choices are determined by a mix of random conditions such as gender, social status, income, perceived burden and working times [8-11]. As a result, even if the appropriate number of physicians to be trained to respond to population needs could be accurately forecasted, major imbalances would still persist, some medical specialities being more popular than others. This is why an increasing number of countries rely on foreign trained physicians' immigration to compensate for temporary or persistent physician shortage. This has recently been referred to as a "quick and inexpensive fix" for under-planning of workforces [7]. The report on Healthcare workforce in OECD countries (period 1995-2005), shows that for instance Australia, Canada, New Zealand, Norway, the United Kingdom and Switzerland are the six OECD countries where physician immigration rates exceed medical graduation rates. With 9.7 new medical graduates per 100,000 inhabitants in 2012, Switzerland is below the median of 10.4 graduates per 100000 residents of other OECD countries. Unsurprisingly, Switzerland has become increasingly dependent on foreign medical trainees, particularly in hospitals and surgical/anaesthetic specialties [12]. Currently $32.6 \%$ of anaesthetists and surgeons trainees had their medical diploma delivered outside Switzerland [13].

Despite high needs of foreign medical graduates, a number of countries have implemented restrictive policies that limit either duration of stay, clinical privileges or the number of residency permits allocated to migrating physicians. For instance, the United States have developed a 'cultural exchange visa' that allows foreign graduates to stay for only a limited period of time before being required to return home for a two-year period after which he/she is entitled to apply for re-entry again [14]. Switzerland is considering the implementation of a restrictive quota policy for new immigrants, including skilled workers. A strictly predefined number of working and residency permits would be delivered to foreigners, whenever planned residency exceeds four months [15]. Such limitations to skilled workers mobility may have detrimental effects on the overall size of the physician healthcare workforce, particularly in countries that highly rely on foreign immigration. The true impact of such policies is however currently unknown, particularly in specialties like anaesthesia known to be sensitive to workforce containment policies $[8,16]$.
The purpose of this study was therefore to model the impact of a restrictive policy based on strict annual quotas of residency permits for migrating physicians in a case study of anaesthesia in Switzerland.

\section{Methods \\ Study design}

Data were extracted from a cross-sectional study assessing all anaesthetists (in training or certified) practicing anaesthesia as a main activity, in public or private hospitals in all the French and Italian speaking cantons of Switzerland [17]. In order to assess all trainees including those from foreign countries, participants were included through local professional organisations and hospital lists prepared in each canton by two coordinators, one for private and the other for public hospitals. While the original questionnaire sent to participants included 103 items gathering information on demographic characteristics, professional activity and satisfaction, for the modelling study we used a restricted number of variables. These were age, gender, type of professional training, country of origin and diploma, professional activity, type of institution, position, activity ratio, professional life plan and desired retirement age. Details of the questionnaire used for the study are provided in a previous publication [18]. To assess density and other variables requiring population data, we used information available from the OECD healthcare database and from the Swiss Federal Institute of Statistics in Neuchâtel.

University and hospital human research ethics committee approval was not required for this study, as no patient health-related or sensitive information were collected.

\section{Statistical analysis}

In our study context, inflow was based on fixed constraints (quotas of foreign physicians allowed to practice in Switzerland). Therefore we could not use traditional inflow or combined inflow/outflow models $[4,19]$. We developed a computer-based Markov model to project the number of anaesthetists and their respective position (in training, transition, fixed or retired) until 2024. In Markov models, transition probabilities from one state to another are estimated according to a number of factors. They are particularly appropriate in workforce studies forecasting human labour market according to a number of predefined constraints [20, 21]. In our model, we considered that factors affecting demand were: official and desired retirement age (when expressed), gender, demographic distribution of existing workforce, number of long term positions available (consultant in a private or public hospital, leading positions in public hospitals, office-based anaesthesia) and age of diploma. The supply-side assumption of the model was that, according to a strict return policy, fixed quotas of foreign 
trainees entering anaesthesia workforce would be implemented and remain constant over the years. Transition probability between training position (internship), transition positions (senior registrars) and fixed positions (consultants in a private or public hospital, leading positions in public hospitals, out-office positions) were determined by the number of individuals in training, the duration of training, favoured retirement age, gender and number of part/full time positions. Because these factors are interlinked, we used Monte Carlo simulations. These are based on mathematical algorithms which allow the construction of hypothetical cohorts that integrate the coupling of interlinked factors. These factors define the transition probabilities to move from one state to another in the Markov model [22]. Therefore Monte Carlo simulations are particularly sound for coupled variables with several degrees of freedom. In our study transition probabilities from one state to another (i.e. fixed position to retirement) was conditioned by several coupled factors such as age, gender, part/full time work, individual preferences.

Our model's assumptions were that quota policies would limit training positions to a constant proportion of foreign trainees and that senior positions (fixed positions) would constantly be filled by the existing pool of anaesthetists in transition positions (senior registrars). Results are reported as absolute numbers with $95 \%$ CI.

Socio-demographic characteristics and professional activity were described using frequency tables and proportions. Continuous variables such as age and working hours were transformed into separate and mutually exclusive categories. For other continuous variables like retirement age we used means and standard deviations. The number and density of medical students graduating from Swiss universities were extracted from the OECD health database (Fig. 1).

Data are reported as absolute numbers and proportions per 100000 inhabitants [23]. Statistical analyses were performed with Stata/IC 12.0 (Stata-Corp, College station) and S-Plus 8.0 for Windows (Insightful Corp., Seattle).

\section{Results}

\section{Anaesthetists' characteristics}

Overall, $416(82 \%)$ of the 506 listed anaesthetists (in training or certified) practising in the Latin (French or Italian-speaking) cantons of Switzerland, provided responses to the survey that could be used for the modelling study. Participants' characteristics and the distribution of the variables integrated into the model are summarised in
Table 1 . The proportion of men was $58 \%$ and the majority of anaesthetists was aged between 36 to 55 years. The proportion of trainees was higher amongst anaesthetists from foreign origin $(32 \%)$ than amongst Swiss nationals $(13 \%)$. While the later practiced mainly in private $(25 \%)$ and university-affiliated hospitals (40\%), European and extra-European anaesthetists were mainly working in district hospitals (49\%). There were $24 \%$ of anaesthetists working part-time and desired retirement age was lower in female (60 years) than in male anaesthetists (62 years). For all of them it was lower than the legal retirement age in Switzerland, 64 years for females and 65 years for males. While the official duration of specialty training for anaesthesia in Switzerland is 5 years, the median interval between graduation and certification was in fact 9 years (Table 1$)$.

\section{Modelling study results}

The model shows a progressive increase in the number of anaesthetists retiring by 2024, on average 8 to 12 (95\% CI 4-20) per year (Fig. 2a). If a strict regulation of foreign trainees admitted to work in Switzerland was implemented, a fixed number of physicians would fill the training positions resulting in a progressive imbalance in the number of anaesthetists in transition positions. Data resulting from the modelling process (Table 2) confirm that the number of anaesthetists in transition positions (senior registrars) would be $38 \%$ below the number that would actually be necessary by 2024 .

When modelling the impact of part time work on the total size of the workforce, a gap would already appear by the end of the year 2014 with $10 \%$ of full-time equivalent transition positions not being filled. The gap would reach $50 \%$ (95\% CI 42-59) by the end of 2024 (Fig. 2b). This lack of senior registrars in transition positions would be particularly important in district hospitals where nearly half ( $49 \%$ ) of the non-Swiss anaesthetists are practising (Table 1). This could theoretically be compensated by an increase in the number of medical graduates from Swiss universities. Data extracted from the OECD health database show that this cannot be the case. While the absolute number of new medical graduates increased by $8 \%$ (from 756 to 813 ) between 2000 and 2010, the growth of the Swiss population resulted in an overall decrease of the rate of new graduates per 100000 inhabitants, from 10.5 to 10.3 in 2010 . This deficit increased even further in 2012, with a rate of 9.7 new graduates per 100000 inhabitants (Fig. 3).

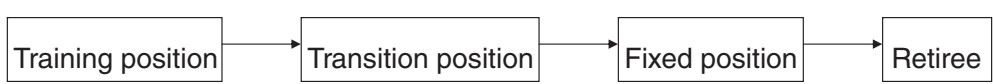

Fig. 1 Diagram of the four-state Markov model used to predict the distribution of anaesthetists 
Table 1 Distribution of variables used in the model

\begin{tabular}{|c|c|c|c|}
\hline Variables & N (\%) & Variables & N (\%) \\
\hline Age & & Nationality & \\
\hline$\leq 35$ y & $97(24)$ & Swiss & $338(81)$ \\
\hline $36-55$ y & $254(62)$ & European & $69(17)$ \\
\hline$\geq 56 y$ & $56(14)$ & Others & $6(2)$ \\
\hline Gender & & Type of activity & \\
\hline Female & $171(42)$ & All anaesthetists & \\
\hline Male & $239(58)$ & Fixed (Consultant, Head; Out-office) & $248(60)$ \\
\hline Working hours/week & & Transition (senior registrar) & $99(24)$ \\
\hline$\leq 50 \mathrm{~h}$ & $187(49)$ & Training (intern, registrar) & $66(16)$ \\
\hline $51-69 \mathrm{~h}$ & $161(42)$ & Swiss & \\
\hline$\geq 70 \mathrm{~h}$ & $41(9)$ & Fixed (Consultant, Head; Out-office) & $218(64)$ \\
\hline Full/part time & & Transition (senior registrar) & $80(23)$ \\
\hline Part-time & $97(24)$ & Training (intern, registrar) & $42(13)$ \\
\hline Full-time & $315(76)$ & European-extra-european & \\
\hline Desired retirement age & & Fixed (Consultant, Head; Out-office) & $31(41)$ \\
\hline Males, Years (mean SD) & $62(3.1)$ & Transition (senior registrar) & $20(27)$ \\
\hline Females, Years (mean SD) & $60(2.8)$ & Training (intern, registrar) & $24(32)$ \\
\hline FMH title* & & Type of hospital & \\
\hline No & $109(28)$ & All anaesthetists & \\
\hline Yes & $288(72)$ & University hospital & $161(39)$ \\
\hline Duration of specialty training if $\mathrm{FMH}$ title* & & District hospital & $155(28)$ \\
\hline 5 years & $10(4)$ & Private & $92(22)$ \\
\hline 6 years & $32(12)$ & Office-based & $2(0)$ \\
\hline 7 years & $42(16)$ & Swiss & \\
\hline 8 years & $36(13)$ & University hospital & $133(40)$ \\
\hline 9 years & $31(12)$ & District hospital & $119(35)$ \\
\hline 10 years & $36(13)$ & Private & $82(24)$ \\
\hline 11 years & $24(9)$ & Office-based & $2(1)$ \\
\hline 12 years & $15(6)$ & European-extra-european & \\
\hline 13 years & $10(4)$ & University hospital & $28(38)$ \\
\hline 14 years & $7(3)$ & District hospital & $36(49)$ \\
\hline \multirow[t]{2}{*}{15 years and more } & $25(9)$ & Private & $10(13)$ \\
\hline & & Office based & $0(0)$ \\
\hline
\end{tabular}

*Specialty title of the Swiss Medical Association (FMH).

\section{Discussion}

Using a Markov supply and demand forecasting model, we found that a strict regulation of foreign physicians admitted in anaesthesia training positions in Latin Switzerland would result in a progressive and significant shortage of $38 \%$ in the number of anaesthetists in transition positions by the year 2024 . When adding to the model the impact on favoured retirement age of the increasing female to male ratio and the progressive societal shift from full to parttime job, this gap could reach $50 \%$ (95 \% CI 42-59) by the end of the projection period. This could have a serious impact on public hospitals but more particularly on district hospitals, where nearly half of the European and extra-European anaesthetists are practising. This case study shows that in countries that heavily rely on foreign physicians to maintain their healthcare workforce balance, the implementation of restrictive policies such as strict quotas (i.e. Switzerland) or return policies (i.e. United States) are likely to cause a significant deficit in physician workforce, particularly in district areas. 


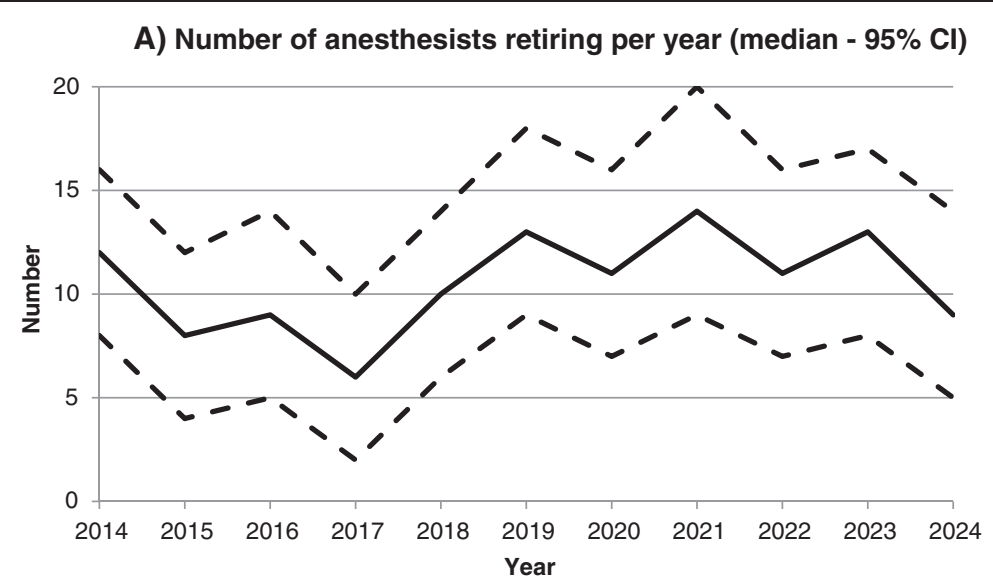

B) Percentage $(95 \% \mathrm{Cl})$ of full time transition positions filled

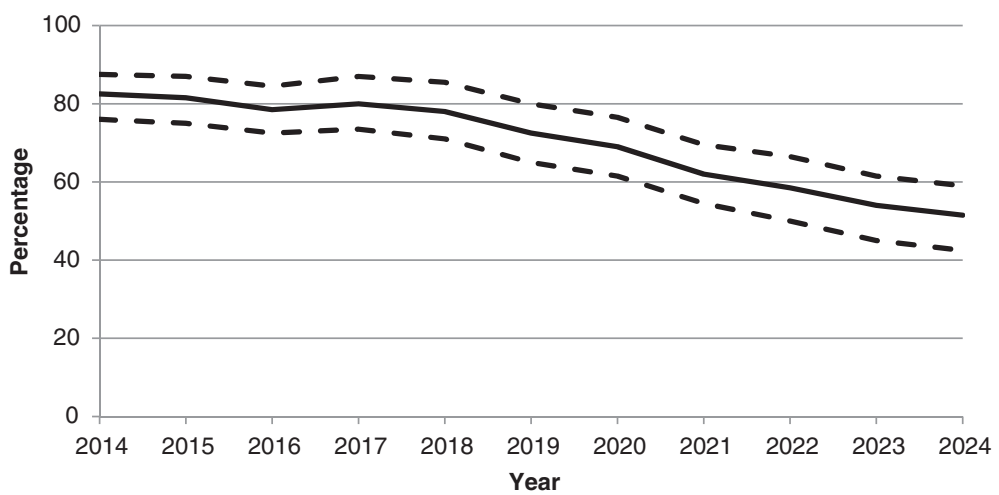

Fig. 2 Number of anaesthetists retiring by age category. a Number of anesthesists retiring per year (median - $95 \%$ Cl). b Percentage (95\% Cl) of full time transition positions filled

While the impact of a restrictive policy on trained physicians' immigration has not been assessed elsewhere, a number of related publications confirm our findings. In a study on Austrian psychiatrists, Riedel et al. found that the implementation of quotas for different nationalities at entry in medical school was one of the main contributor to the projected $5 \%$ gap between demand and supply in 2030 [24]. In another modelling study on optometric supply in Australia, Kiely et al. forecasted a $21.5 \%$ decline in the proportion of optometrists in active practice if the number of national graduate and immigrants was going to decrease in the future [25].

Therefore, when the provision of locally trained physicians is insufficient to meet population needs, countries

Table 2 Distribution of the number of anaesthetists predicted by the model ( $\mathrm{N}, 95 \% \mathrm{Cl}$ )

\begin{tabular}{|c|c|c|c|c|}
\hline Year & Training position & Transition positions & Fixed positions & Retirees \\
\hline 2014 & 66 (66 to 66) & 93 (86 to 98) & 244 (241 to 247) & 12 (8 to 16$)$ \\
\hline 2015 & 66 (66 to 66$)$ & 92 (85 to 98 ) & 244 (241 to 247 ) & 8 (4 to 12$)$ \\
\hline 2016 & 66 (66 to 66$)$ & 89 (82 to 95$)$ & 244 (241 to 248 ) & $9(5$ to 14$)$ \\
\hline 2017 & 66 (66 to 66$)$ & 90 (83 to 98$)$ & 244 (241 to 248 ) & 6 (2 to 10$)$ \\
\hline 2018 & 66 (66 to 66$)$ & 88 (80 to 96$)$ & 244 (240 to 247 ) & 10 (6 to 14$)$ \\
\hline 2019 & 66 (66 to 66) & 81 (74 to 89) & 244 (240 to 248 ) & 13 (9 to 18$)$ \\
\hline 2020 & 66 (66 to 66$)$ & 78 (70 to 85$)$ & 244 (240 to 248 ) & 11 (7 to 16$)$ \\
\hline 2021 & 66 (66 to 66) & 70 (61 to 77$)$ & 245 (241 to 249) & 14 (9 to 20$)$ \\
\hline 2022 & 66 (66 to 66$)$ & 66 (57 to 73$)$ & 244 (240 to 249) & 11 (7 to 16$)$ \\
\hline 2023 & 66 (66 to 66) & 60 (51 to 68) & 244 (240 to 249) & 13 (8 to 17$)$ \\
\hline 2024 & 66 (66 to 66) & 58 (49 to 66$)$ & 244 (239 to 249) & 9 (5 to 14$)$ \\
\hline
\end{tabular}




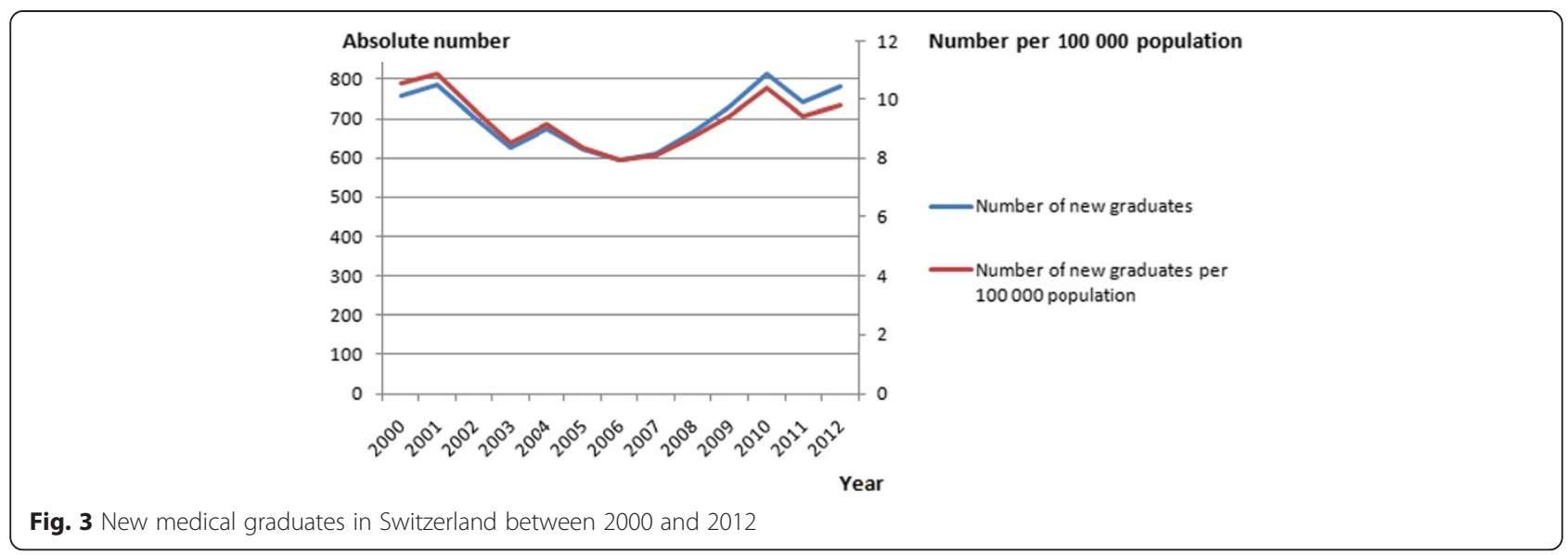

should engage in policies facilitating rather than impeding immigration. However, these should be considered only as temporary buffers as such policies are likely to further increase the brain drain already present in numerous countries [26, 27]. Western OECD countries are currently the main destination for medical migrants while developing and East European countries experience a progressive shortage of physicians due to emigration [28]. The brain drain of physicians has a serious negative impact on healthcare systems of countries with a negative immigration balance [29, 30]. Therefore, a number of specific guidelines and codes of good practice have been developed to promote ethical, transparent, fair and mutually beneficial agreements between source and destination countries [14].

Some examples are the Commonwealth Code of Practice for International Recruitment of Health Workers [31] and the 'Global Code of Practice on the International Recruitment of Health Personnel' of the World Health Organisation [32]. While such policies are laudable initiatives, their impact on the brain drain of skilled healthcare workers from developing countries remains marginal. Codes of practice are voluntary initiatives of the signatories and compliance is hardly monitored or enforced [33]. Governance in the field of human resources for health remains relatively poor [34].

Interestingly, extensive policies aimed at limiting immigration, while integrating little ethical considerations, are likely to have a more significant impact on brain drain than codes of good practices. In our case study, we forecasted a $50 \%$ (95\% CI 42-59) decrease (adjusted for part-time positions) within 10 years of the number of anaesthetists in intermediary positions (senior registrars), should strict immigration quotas for foreigners be implemented in Switzerland.

It could be argued that immigrants contribute to increase the size of the population and thus, a strict regulation of immigration could maintain the balance of the physician to population ratio. However, this ignores the increased demand of the population for care, particularly in the surgical area. In Switzerland for instance, between 2002 and 2008 there has been a19 \% increase in the overall number of core surgical procedures (inpatient and outpatient) [35]. A similar trend has been observed in most OECD countries where healthcare needs have increased [36], particularly for surgical procedures such as hip or knee replacement, with a 10 to $60 \%$ raise between 2000 and 2010. As a result, limiting global immigration is likely to have no impact on the growing need for additional physicians.

To minimise reliance on foreign trained physicians and limit the brain drain of physicians in source territories, countries should engage in policies that increase domestic physician supply. These should not be done only through quota adjustments of medical students [37], but also through initiatives that tend to improve the retention of physicians in the workforce. This could be done by increasing retirement age and working hours. However, these should be in line with both the generation shift and existing laws defining retirement age and regulating the maximum amount of working hours authorized for physicians. In Switzerland, these are set at $50 \mathrm{~h}$ a week [38-40].

Another option, in the case of anaesthesia care, could be the implementation of independent anaesthesia nurse practitioners. In Switzerland, nurse anaesthetists are a significant part of the anaesthesia workforce and are allowed to perform a large number of procedures such as drug administration, tracheal intubation, patient monitoring and surveillance. These have to be performed under the strict supervision of a certified anaesthetist. In the near future, they could provide anaesthesia care without any assistance in low risk ASA 1 and 2 patients.

There is to date much controversy as to whether this approach would be detrimental or not to the overall quality of care [41, 42]. Professional organizations are still debating whether or not, they should engage in that direction. Furthermore, the recruitment of nurses can be quite difficult and many countries suffer from a nurses' 
workforce shortage. As a result, Switzerland like many other European countries heavily relies on foreign trained nurses to care for its population [43].

Another alternative could be to increase productivity through technological innovation, financial incentives such as fee-for-service payments and the development of day care surgery $[44,45]$. Some of these developments are already underway. For instance, an increasing number of surgical procedures in Switzerland are performed on a day care basis, increasing patient turnover in hospitals and overall productivity. Replacing cost-reimbursement by activity-based payments that reward efficiency is another possible method that could enhance productivity [46]. This strategy should be balanced with the increased risk of jeopardizing the overall quality of the service provided, if patient turnover is escalated excessively. In healthcare, productivity cannot be increased perpetually and a minimum staff/patient ratio needs to be achieved in order to minimize the risk of adverse outcomes $[1,3]$. This is especially true in anaesthesia, a high risk specialty [47-49].

There are a number of limitations to our study. First, in our model, we assumed that over the years, only fixed and constant quotas of non-Swiss trainees would be allowed to work and live in the country. While this is likely to be the case with the new law, the exact outline of the Swiss quota immigration policy is currently still under consideration. Our model is therefore only one of the several possible scenarios that may result from the new immigration policy. Secondly, the model included only data collected in the French- and Italian-speaking part of Switzerland, limiting the generalisability of study findings. Finally, we lacked information on anaesthetists working in intensive care and could not draw conclusions on this category of healthcare professionals although they contribute to post anaesthesia care. Despite these limitations, the present study is the first one to assess the possible impact of restrictions on skilled immigration in a case study of the specialty of anaesthesia. Future studies should explore the impact of such policies in other medical specialties and other OECD countries that heavily rely on skilled immigration to supply healthcare to their home population. It would also be important to perform such studies in nursing, midwifery and other allied healthcare workforce areas which also often rely on skilled immigration in many countries.

\section{Conclusions}

This case study of anaesthesia care in Switzerland shows that insufficient provision of locally trained medical graduates combined to a policy limiting entry of foreign trainees is likely to cause a major deficit in the number of anaesthetists available to meet population needs. In the context of growing physician shortages in many OECD countries, migration flows can offer temporary solutions to erroneous healthcare workforce planning and increased population needs. These should however only be considered as short-term buffers as they contribute to the brain drain of physicians in countries where they are highly needed. Instead, countries should engage in policies that can create adequate supplies of domestic physicians by enhancing education and training whilst at the same time improving methods of retention of the existing workforce.

\section{Competing interests}

The authors declare that they have no competing interests.

\section{Authors' contributions}

GH, CC, CM, DZ, FC participated to the study concept, design and/or data collection; $\mathrm{GH}, \mathrm{CC}$ performed the statistical analysis and interpretation of the data; GH, CC drafted the first version of the manuscript; CM, DZ, FC performed a critical revision of the manuscript for important intellectual content; all authors had full access to the study data, take responsibility for their integrity and accuracy and have given final approval for the publication of the manuscript.

\section{Acknowledgements}

The authors would like to thank all the members of the commission for anaesthesia training of Latin Switzerland (COMASUL) as well as the study local coordinators, Drs A. Delachaux, P. Mondragon, N. Milliet, P. Gosteli,

A. Schweitzer, M. Ross, P. Flubacher, T. Cassina, G. Casso, A-S. Eichenberger, S. De Cupis and Prs. Ch. Kern, P. Ravussin for their help in the setting up of the study and data collection process.

We are also grateful to Mrs Anne-Gabrielle de Haller who coordinated the data collection process and contributed to the setting up of the whole study organisation.

\section{Author details}

${ }^{1}$ Division of Anaesthesia, Department of Anaesthesiology, Pharmacology and Intensive Care University Hospitals of Geneva, 4, rue Perret-Gentil, 1211 Genève 14, Switzerland. ${ }^{2}$ Health Services Management and Research Unit, Department of Epidemiology \& Preventive Medicine, Monash University, Melbourne, Australia. ${ }^{3} \mathrm{CRC}$ and Division of Clinical Epidemiology, Department of Health and Community Medicine, University of Geneva, University Hospitals of Geneva, Geneva, Switzerland.

Received: 11 December 2014 Accepted: 12 May 2015

Published online: 22 May 2015

\section{References}

1. Goodman DC, Fisher ES, Little GA, Stukel TA, Chang CH. Are neonatal intensive care resources located according to need? Regional variation in neonatologists, beds, and low birth weight newborns. Pediatrics. 2001;108(2):426-31.

2. Gulliford MC. Availability of primary care doctors and population health in England: is there an association? J Public Health Med. 2002;24(4):252-4.

3. Needleman J, Buerhaus P, Mattke S, Stewart M, Zelevinsky K. Nurse-staffing levels and the quality of care in hospitals. N Engl J Med. 2002;346(22):1715-22.

4. Dussault GBJ, Sermeus W, Padaiga Z. Assessing Future Health Workforce Needs. Policy Summary 2. Copenhagen-Denmark: World Health Organization on behalf of European Observatory on Health Systems and Policies; 2010.

5. Roberfroid D, Leonard C, Stordeur S. Physician supply forecast: better than peering in a crystal ball? Hum Resour Health. 2009;7:10.

6. European Commission: EU level Collaboration on Forecasting Health Workforce Needs, Workforce Planning and Health Workforce Trends - A Feasibility Study. [http://ec.europa.eu/health/workforce/key_documents/ study_2012/index_en.htm]

7. Health Policy Studies OECD. The Looming Crisis in the Health Workforce. Paris: OECD Publishing; 2008.

8. Dorsey ER, Jarjoura D, Rutecki GW. Influence of controllable lifestyle on recent trends in specialty choice by US medical students. JAMA. 2003;290(9):1173-8.

9. Lambert EM, Holmboe ES. The relationship between specialty choice and gender of U.S. medical students, 1990-2003. Acad Med. 2005;80(9):797-802. 
10. Newton DA, Grayson MS, Thompson LF. Money, lifestyle, or values? Why medical students choose subspecialty versus general pediatric careers. Clin Pediatr (Phila). 2010;49(2):116-22.

11. Hauer KE, Durning SJ, Kernan WN, Fagan MJ, Mintz M, O'Sullivan PS, et al. Factors associated with medical students' career choices regarding internal medicine. JAMA. 2008;300(10):1154-64.

12. Dumont J-C, Zurn P, Sopemi. Immigrant Health Workers in OECD Countries in the Broader Context of Highly Skilled Migration. In: International Migration Outlook. 2007. p. 161-228. OECD (Series Editor).

13. Swiss Science and Technology Council: Démographie médicale et réforme de la formation professionnelle des médecins; Swiss confederation ed. Bern; 2007.

14. Forcier MB, Simoens S, Giuffrida A. Impact, regulation and health policy implications of physician migration in OECD countries. Hum Resour Health. 2004;2(1):12

15. Swiss Federal Council: Federal Council presents concept for implementing the new article on immigration. [https://www.news.admin.ch/message/ index.html?lang=en\&msg-id=53415]

16. Gautier JF, N'Guyen JL, Soltner C, Beydon L. French residents in anaesthesia and critical care - a nationwide survey. Ann Fr Anesth Reanim. 2004;23(8):794-8.

17. Mamie C, Clergue F, Zocatelli D, Haller G. Swiss healthcare cost containment policies and their impact on anaesthetists' density and satisfaction. Swiss Med Wkly. 2011;141:w13251.

18. Mamie C, Meyer P. Evolution prévisible des effectifs médico-infirmiers en anesthésie en Suisse romande. Rev Med Suisse. 2004;491:1-9.

19. Van Greuningen M, Batenburg R, Van der Velden L. Ten years of health workforce planning in the Netherlands: a tentative evaluation of GP planning as an example. Hum Resour Health. 2012;10:21.

20. Deal CL, Hooker R, Harrington T, Birnbaum N, Hogan P, Bouchery E, et al. The United States rheumatology workforce: supply and demand, 2005-2025. Arthritis Rheum. 2007:56(3):722-9.

21. Lagarde M, Cairns J. Modelling human resources policies with Markov models: an illustration with the South African nursing labour market. Health Care Manag Sci. 2012;15(3):270-82.

22. Sonnenberg FA, Beck JR. Markov models in medical decision making: a practical guide. Med Decis Making. 1993;13(4):322-38.

23. Organisation for Economic Co-Operation and Development: OECD Health Data 2013. [http://www.oecd-ilibrary.org/]

24. Riedel M, Roehrling G, Czypionka T, Kasper S. A gap analysis for future supply of and demand for psychiatrists in Austria. J Ment Health Policy Econ. 2014;17(1):9-18.

25. Kiely PM, Healy E, Horton P, Chakman J. Optometric supply and demand in Australia: 2001-2031. Clin Exp Optom. 2008;91(4):341-52.

26. Mullan F. The metrics of the physician brain drain. N Engl J Med. 2005:353(17):1810-8

27. International Organization for Migration. Managing Labour Mobility in the Evolving Global Economy; International organisation for migration ed. Geneva; 2008.

28. Buchan J. How can the migration of health professionals be managed so as to reduce any negative effects on supply. Policy Brief Series. WHO Europe 2008.

29. Kirigia JM, Gbary AR, Muthuri LK, Nyoni J, Seddoh A. The cost of health professionals' brain drain in Kenya. BMC Health Serv Res. 2006;6:89.

30. Mills EJ, Kanters S, Hagopian A, Bansback N, Nachega J, Alberton M, et al. The financial cost of doctors emigrating from sub-Saharan Africa: human capital analysis. BMJ. 2011;343:d7031.

31. Commonwealth Health Ministers: Commonwealth Code of Practice for International Recruitment of Health Workers. [http:// www.commonwealthpharmacy.org/wp-content/uploads/2009/06/ Commonwealth-Code-of-Practice-for-Health-Workers.pdf]

32. World Health Organisation: Global Code of Practice on the International Recruitment of Health Personnel. [http://www.who.int/hrh/migration/code/ WHO_global_code_of_practice_EN.pdf]

33. Aluttis C, Bishaw T, Frank MW. The workforce for health in a globalized contextglobal shortages and international migration. Glob Health Action. 2014;7:23611.

34. Dieleman M, Shaw DM, Zwanikken P. Improving the implementation of health workforce policies through governance: a review of case studies. Hum Resour Health. 2011;9:10.

35. Organisation for Economic Co-Operation and Development: OECD Health Care utilisation 2013. [http://www.oecd-ilibrary.org/]
36. Organisation for Economic Co-Operation and Development: Health at a Glance: Europe 2012. [http://dx.doi.org/10.1787/9789264183896-en]

37. Coste $E$, Doan BD. Forecast of physician workforce in the 22 French regions (1998-2013). Cah Sociol Demogr Med. 2003;43(1):5-70.

38. Cohen JJ. Our compact with tomorrow's doctors. Acad Med. 2002;77(6):475-80.

39. Sheahan P. Generation Y: thriving and surviving with Generation Y at work. Prahran, Victoria: Hardy Grant; 2005.

40. Waurick R, Weber T, Broking K, Van Aken H. The European Working Time Directive: effect on education and clinical care. Curr Opin Anaesthesiol. 2007;20(6):576-9.

41. Clergue F. Time to consider nonphysician anaesthesia providers in Europe? Eur J Anaesthesiol. 2010;27(9):761-2.

42. Lange $M$, Prien $T$, Brussel $T$, Van Aken $H$. The anaesthetist makes a difference: the bottom line matters! Eur J Anaesthesiol. 2011;28(4):306-7.

43. Wismar MGI, Maier CB, Dussault G, Palm W, Bremner J, Figueras J. Health professional mobility and health systems: evidence from 17 European countries. Euro Observer. 2011;13(2):1-4.

44. Bloor K, Maynard A. The productivity of health care. Health Econ. 2006;15(12):1257-9.

45. Studies OHP. The Looming Crisisin the Health Workforce. 2008.

46. OECD. Towards High-Performing Health Systems. Paris: OECD; 2004.

47. Bixenstine PJ, Shore AD, Mehtsun WT, Ibrahim AM, Freischlag JA, Makary MA. Catastrophic medical malpractice payouts in the United States. J Healthc Qual. 2014;36(4):43-53.

48. Staender $\mathrm{S}$, Schaer $\mathrm{H}$, Clergue $\mathrm{F}$, Gerber $\mathrm{H}$, Pasch $\mathrm{T}$, Skarvan $\mathrm{K}$, et al. A Swiss anaesthesiology closed claims analysis: report of events in the years 1987-2008. Eur J Anaesthesiol. 2011;28(2):85-91.

49. Campbell G, Rollin AM, Smith AF. Cases relating to anaesthetists handled by the UK General Medical Council in 2009: methodological approach and patterns of referral. Anaesthesia. 2013;68(5):453-60.

\section{Submit your next manuscript to BioMed Central and take full advantage of:}

- Convenient online submission

- Thorough peer review

- No space constraints or color figure charges

- Immediate publication on acceptance

- Inclusion in PubMed, CAS, Scopus and Google Scholar

- Research which is freely available for redistribution 